\title{
Genome-Wide Identification and Expression Analysis of Udp-Glucuronosyltransferases in the Whitefly Bemisia Tabaci (Gennadius) (HemipterA: Aleyrodidae)
}

\author{
Litao Guo ${ }^{1,2,+}$, Wen $\mathrm{Xie}^{2, \dagger}$, Zezhong Yang ${ }^{2}$, Jianping $\mathrm{Xu}{ }^{1,3, * \mathbb{C}}$ and Youjun Zhang ${ }^{2, * \mathbb{C}}$ \\ 1 Institute of Bast Fiber Crops, Chinese Academy of Agricultural Sciences, Changsha 410205, China; \\ guolitao@caas.cn \\ 2 Department of Plant Protection, Institute of Vegetables and Flowers, Chinese Academy of Agricultural \\ Sciences, Beijing 100081, China; xiewen@caas.cn (W.X.); yyll88523@126.com (Z.Y.) \\ 3 Department of Biology, McMaster University, Hamilton, ON L8S 4K1, Canada \\ * Correspondence: jpxu@mcmaster.ca (J.X.); zhangyoujun@caas.cn (Y.Z.) \\ + These authors have contributed equally to this work.
}

Received: 9 October 2020; Accepted: 9 November 2020; Published: 11 November 2020

\begin{abstract}
Bemisia tabaci (Gennadius) (Hemiptera: Aleyrodidae) is an important agricultural pest worldwide. Uridine diphosphate (UDP)-glucuronosyltransferases (UGTs) are one of the largest and most ubiquitous groups of proteins. Because of their role in detoxification, insect UGTs are attracting increasing attention. In this study, we identified and analyzed UGT genes in B. tabaci MEAM1 to investigate their potential roles in host adaptation and reproductive capacity. Based on phylogenetic and structural analyses, we identified 76 UGT genes in the B. tabaci MEAM1 genome. RNA-seq and real-time quantitative PCR (RT-qPCR) revealed differential expression patterns of these genes at different developmental stages and in association with four host plants (cabbage, cucumber, cotton and tomato). RNA interference results of selected UGTs showed that, when UGT352A1, UGT352B1, and UGT354A1 were respectively silenced by feeding on dsRNA, the fecundity of $B$. tabaci MEAM1 was reduced, suggesting that the expressions of these three UGT genes in this species may be associated with host-related fecundity. Together, our results provide detailed UGTs data in $B$. tabaci and help guide future studies on the mechanisms of host adaptation by $B$. tabaci.
\end{abstract}

Keywords: UDP-glucuronosyltransferases; Bemisia tabaci; adaptability; fecundity; RNAi

\section{Introduction}

Plants and insects are among the most common organisms on earth. Together, they make up approximately half of all known species of multicellular organisms. Plants and insects interact with each other in multiple ways, as mutualists, antagonists, or commensals. A very common form of interaction between insects and plants with significant agricultural and economic importance is insect herbivory on crop plants. In this interaction, insects feed on plants that can cause significant damage to the plants. However, over time, host plants may evolve resistance mechanisms by evolving morphological structures and/or biochemical pathways, e.g., synthesizing and secreting toxic substances, against insects. In turn, herbivorous insects may evolve specific counter mechanisms towards specific host plants. The result of such an arms race can lead to increased specialization of insects feeding only certain plants [1,2]. Alternatively, the insect may change its feeding behavior and expand its feeding range, evolving resistance mechanisms to feed on multiple plant species. Indeed, polyphagous insects are commonly found in nature. One example of a polyphagous insect is the two-spotted spider mite, 
Tetranychus urticae Koch (Acari: Tetranychidae), a generalist herbivore that feeds on many crop and ornamental plants. Indeed, Tetranychus urticae is a model species for understanding the adaptation mechanism of insects to host plants. Genome sequence and functional analyses have identified a variety of adaptation mechanisms in T. urticae, including expansion of genes coding for detoxification enzymes, such as cytochrome P450 monooxygenases, carboxyl-choline esterases, and glutathione-S-transferases, as well as a proliferation of cysteine peptidases, and MFS and ABC transporters [3-6]. In addition, T. urticae has a large repertoire of genes coding for uridine diphosphate (UDP)-glycosyltransferases (UGTs) and intradiol-ring cleavage dioxygenases [7-11]. Comparative analyses revealed that these genes in T. urticae were obtained through horizontal gene transfer but their expressions differed significantly depending on the specific host plants that they feed on [3,6,8,12-14].

UGTs are ubiquitous, found throughout all domains of life, in animals, plants, bacteria and fungi [15]. They catalyze the addition of UDP-sugars to small hydrophobic molecules, turning them into more water-soluble metabolites. In insects, UGTs play an important role in the regulation of endobiotics and in the detoxification of xenobiotics by catalyzing the conjugation of small lipophilic compounds with sugars to produce glycosides [15]. In addition, insect UGT enzymes are activated by a variety of plant allelochemicals $[15,16]$. Several studies have demonstrated that generalist insects can respond to specific secondary metabolites produced by different host plants by inducing changes in gene expression to enhance their fitness on a specific host plant [17-21]. In Helicoverpa armigera, UGT41B3 and UGT40D1 were found associated with detoxification of gossypol [16]. Snoeck et al. reported that multiple compounds of the flavonoid class of plant secondary metabolites were glycosylated by three UGTs (tetur02g09850, tetur22g00270 and tetur22g00440) in T. urticae [11]. In additional, the expression profiles of T. urticae UGT genes changed after host-plant shifts [22]. The expansion of UGTs in the Asian longhorned beetle Anoplophora glabripennis, another polyphagous insect, is also consistent with the role of UGTs in host adaptation [23].

Bemisia tabaci (Gennadius) (Hemiptera: Aleyrodidae), commonly known as the silverleaf whitefly or sweet-potato whitefly, is an important cosmopolitan agricultural pest that causes great damages to agricultural crops [24]. It's been reported that B. tabaci can feed on 74 families and 500 species of host plants [24]. B. tabaci is a species complex, consisting at least 24 morphologically indistinguishable, closely related sibling species with different genetic and biological characteristics [25]. In many parts of the world, two of the species, B. tabaci MEAM1 (Middle East-Asia Minor 1) and B. tabaci MED (Mediterranean) are the most harmful and invasive [25-27]. They can damage plants both directly by feeding on phloem sap, excreting honeydew and indirectly by transmitting over 300 plant viruses [28,29]. In recent years, several studies have been conducted to investigate the interactions of $B$. tabaci and its host plants. The silverleaf whitefly has shown different preference and fitness on different host plants, for example, cotton, cabbage, pepper [30-32]. Its host preference has been found to be affected by host nutrition [33-35] and by specific host metabolites [34,36-39]. However, the underlying molecular mechanism for its differential preference and fitness is largely unexplored.

We have conducted a genome-wide investigation of the UGTs in B. tabaci MEAM1. Our overall goal was to understand the involvement of UGTs in the host adaptability in B. tabaci. We first identified the putative UGT genes from the B. tabaci MEAM1 genome and transcriptome databases. We described the phylogenetic and structural analyses of the B. tabaci MEAM1 UGTs. The expressions of these UGTs were assessed by transcriptomic analysis and real-time quantitative PCR (RT-qPCR) during its different developmental stages and on four host plants. We also verified the function of selected UGT genes in fecundity and survival rate by RNAi. Our results contribute to our understanding of the insect-host interaction and may suggest the potential molecular mechanisms of host plant adaptability in B. tabaci. 


\section{Results}

\subsection{Identification and Phylogenetic Analysis of B. tabaci MEAM1 UGT Genes}

A total of 76 UGT genes were identified in the genome of B. tabaci MEAM1. The detailed information about each UGT gene is listed in Table S1. Following the current nomenclature guidelines of the UGT Nomenclature Committee, UGT genes investigated in this study were submitted to the UGT Nomenclature website (http://prime.vetmed.wsu.edu/resources/udpglucuronsyltransferasehomepage) to identify their current classifications. The identified names are shown in Table S1 [40]. In our study, the UGT gene annotations in the B. tabaci MEAM1 genome were changed due to greater availability of relevant data in databases over the original version by Chen et al. (2016) [41]. Five genes previously thought to be UGT's (Bta01138, Bta02163, Bta07609, Bta09385, Bta09704) have been omitted from our list due to the revised concept of the gene family, while BtaUGT1 has been added to the list (Table S1). The 76 UGT genes in the B. tabaci MEAM1 genome are divided into 15 subfamilies (UGT352, UGT353, UGT354, UGT355, UGT356, UGT357, UGT358, UGT359, UGT360, UGT361, UGT362, UGT363, UGT365, UGT366, UGT50) (Table S1). Among these 76 UGT genes, 46 were distributed in thirteen scaffolds (Figure 1). Specifically, one scaffold (\#297) contained eleven UGT genes (UGT352G1, UGT352G2, UGT352L1, UGT352M1, UGT352Q1, UGT352Q4, UGT352Q5, UGT352Q6, UGT352U1, UGT360A1, UGT360A3). Overall, the number of UGT genes in the B. tabaci MEAM1 genome is similar to several other phytophagous insects and phytophagous mites, for example, Locusta migratoria (68), Acyrthosiphon pisum (72) and Tetranychus urticae (81) (Table 1).

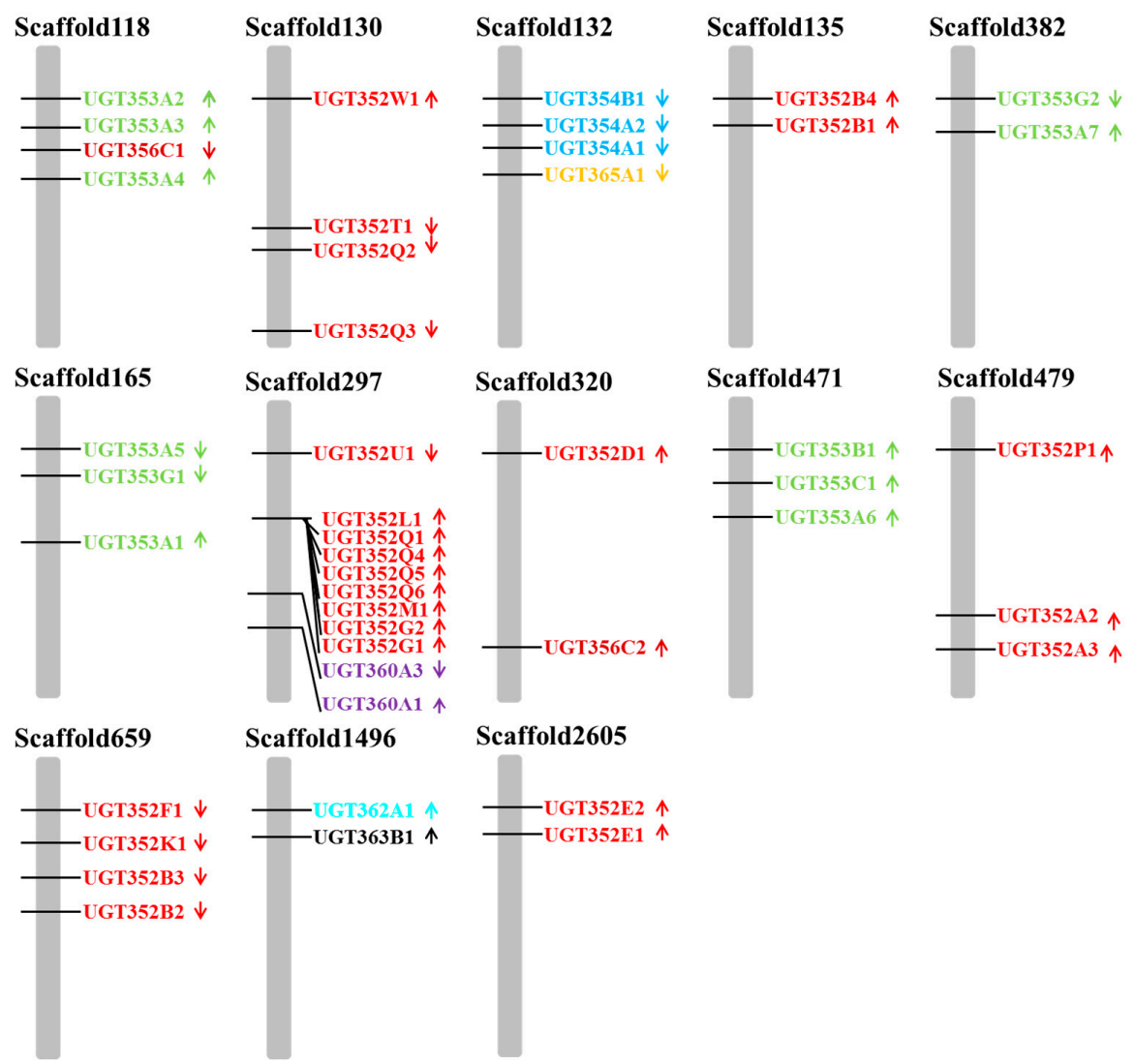

Figure 1. The relative physical positions of UGT genes on scaffolds of the B. tabaci MEAM1 genome. Arrows indicate the transcription direction of UGTs and genes in the same color belong to the same gene family. Accession numbers of UGT protein sequences used are listed in Table S1. Only scaffolds with more than 2 UGTs are shown in this Figure. 
Table 1. The number of UDP-glucuronosyltransferases genes in different insects and mites.

\begin{tabular}{cccc}
\hline Species & Number $^{\text {a }}$ & Food Type & Diet Breadth \\
\hline Bemisia tabaci & 76 & Phytophagous & Polyphagous \\
Tetranychus urticae & 81 & Phytophagous & Polyphagous \\
Acyrthosiphon pisum & 72 & Phytophagous & Polyphagous \\
Locusta migratoria & 68 & Phytophagous & Polyphagous \\
Helicoverpa armigera & 42 & Phytophagous & Polyphagous \\
Diaphorina citri & 37 & Phytophagous & Oligophagous \\
Rhodnius prolixus & 16 & Phytophagous & Oligophagous \\
Danaus plexippus & 35 & Phytophagous & Oligophagous \\
Apis mellifera & 11 & Phytophagous & Oligophagous \\
Nilaparvata lugens & 20 & Phytophagous & Monophagous \\
Bombyx mori & 38 & Phytophagous & Monophagous \\
Nasonia vitripennis & 22 & Carnivorous & Monophagous \\
Camponotus floridanus & 21 & Omnivorous & Polyphagous \\
Tribolium castaneum & 27 & Omnivorous & Polyphagous \\
Anopheles gambiae & 24 & Sanguivorous & Oligophagous \\
Pediculus humanus & 4 & Sanguivorous & Oligophagous \\
Drosophila melanogaster & 35 & Saprophagous & Polyphagous \\
\hline
\end{tabular}

${ }^{a}$ The number of UGT genes in different insects was obtained from reference Chen et al., 2016 [41].

Phylogenetic analyses of the B. tabaci MEAM1 UGTs and UGTs from several other insects were constructed by the neighbor-joining (NJ) method using full-length UGT protein sequences (Figures 2 and 3). In the phylogenetic tree of B. tabaci MEAM1 UGTs, the largest subfamily was UGT352 containing 36 genes and accounting for $47.37 \%$ of all B. tabaci MEAM1 UGT members (Figure 2). The second most abundant subfamily was UGT353, which contained 14 genes in the B. tabaci MEAM1 genome. As expected, the UGT352 subfamily and UGT353 subfamily were clustered into their respectively groups (Figure 2). Among the species, the UGT families of different insects showed a variety of phylogenetic patterns; from conserved subfamilies with one member in each species clustered together like UGT50 (DMUGT50B3, UGT50E1, BMUGT50A1, HAUGT50A2) to large species-specific "blooms" such as UGT344 in aphid (A. pisum). Interestingly, the UGT genes in B. tabaci MEAM1 generally clustered together (Figure 3). In total, two phylogenetic subfamilies, UGT352 and UGT353 appeared to have expanded more than the others during the evolution of the UGT superfamily in B. tabaci MEAM1. UGT50 was the only subfamily found nearly universally distributed in the insects surveyed, composed of one member in each species except the pea aphid. In B. tabaci MEAM1, only one member of the UGT50 subfamily (UGT50E1) was found and it was more similar to UGT50 genes of other insects than to other UGTs from the B. tabaci MEAM1 genome.

\subsection{Expression of the UGT Genes in Different Host Plants and Developmental Stages}

The expression patterns of UGTs were investigated using RNA-seq datasets obtained from $B$. tabaci MEAM1 feeding on four different host plants. In whiteflies of different sexes or feeding on different host plants, the expressions of many UGT genes were different (Figure 4). For example, the expression of UGT352B1 was the highest in females feeding on cabbage, cucumber, tomato and in males feeding on tomato, the expression of UGT353G2 was the highest in females feeding on cotton, and the expression of UGT354A1 was the highest in males feeding on cabbage, cotton and cucumber. The following seven UGTs, UGT352A1, UGT352B1, UGT352B2, UGT353G2, UGT354A1, UGT354A2 and UGT359A1, had significantly different expressions in different host plants. Interestingly, five UGTs (UGT352A1, UGT352B3, UGT352B4, UGT354A1 and UGT360A2) had different expressions between the female and male whiteflies. In all four female samples, two UGT genes UGT353A3 and UGT363A1 were not expressed. In contrast, in the four male samples, three UGT genes, UGT352Q3, UGT352M1 and UGT352W1 were not expressed. The expression levels of 37 UGT genes (UGT352A1-3, UGT352B1-5, UGT352C1, UGT352E1-3, UGT352F1, UGT352L1, UGT352X1, UGT352Y1, UGT353A1, UGT353A5-7, 
UGT353B2, UGT353C1, UGT353G2, UGT354A1-2, UGT355B1, UGT355C1, UGT356A1, UGT356B1, UGT356C1, UGT358A1, UGT359A1, UGT360A2-3, UGT361A1, UGT362A1, UGT365A1) showed more than twofold differences (Table S3) among different host plants.

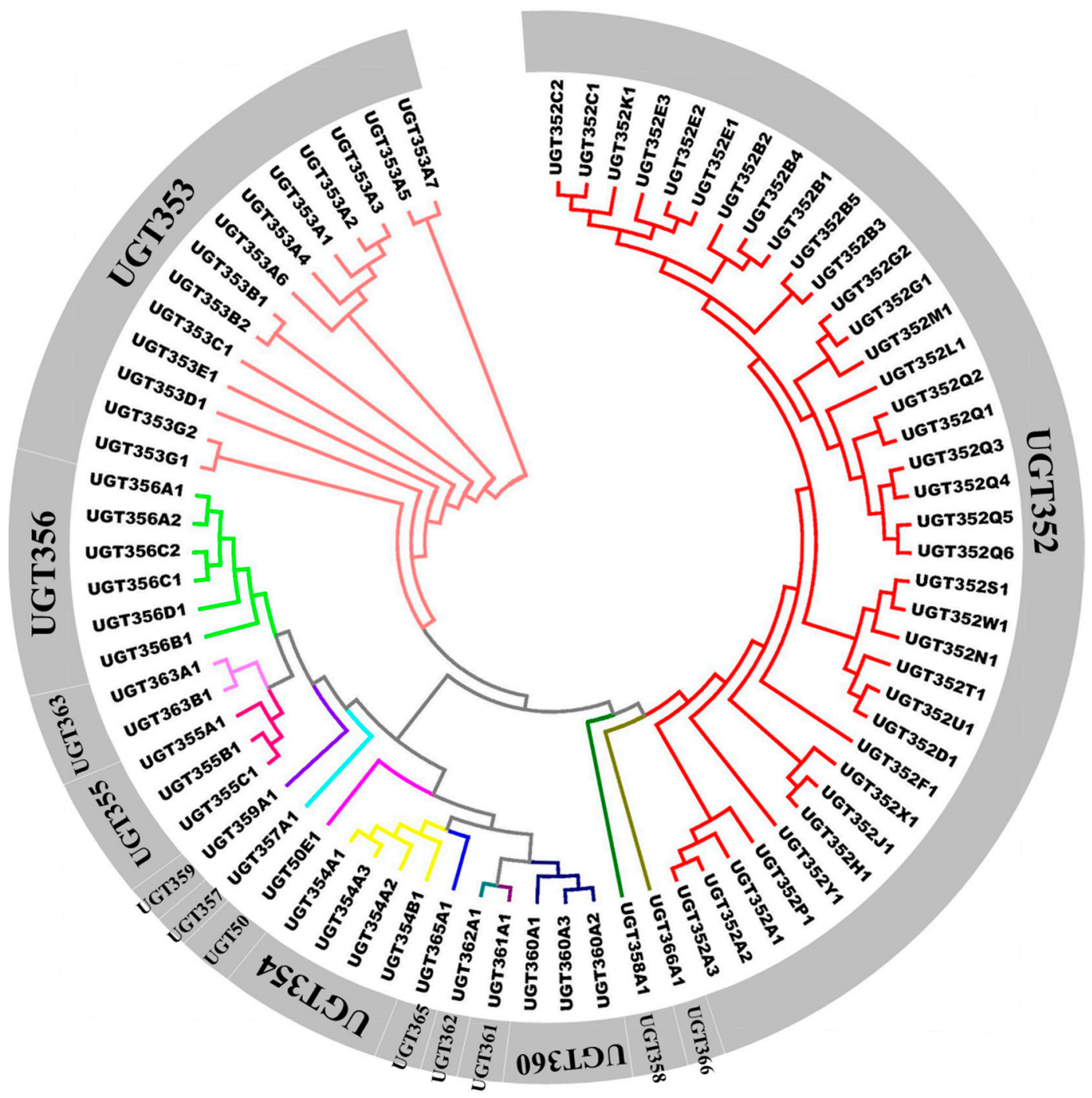

Figure 2. Phylogenetic relationships among the 76 UDP-glucuronosyltransferases (UGTs) in B. tabaci MEAM1. Amino acid sequences were aligned using ClustalW and subjected to a Neighbor-Joining (NJ) analysis by MEGA6 [42]. 


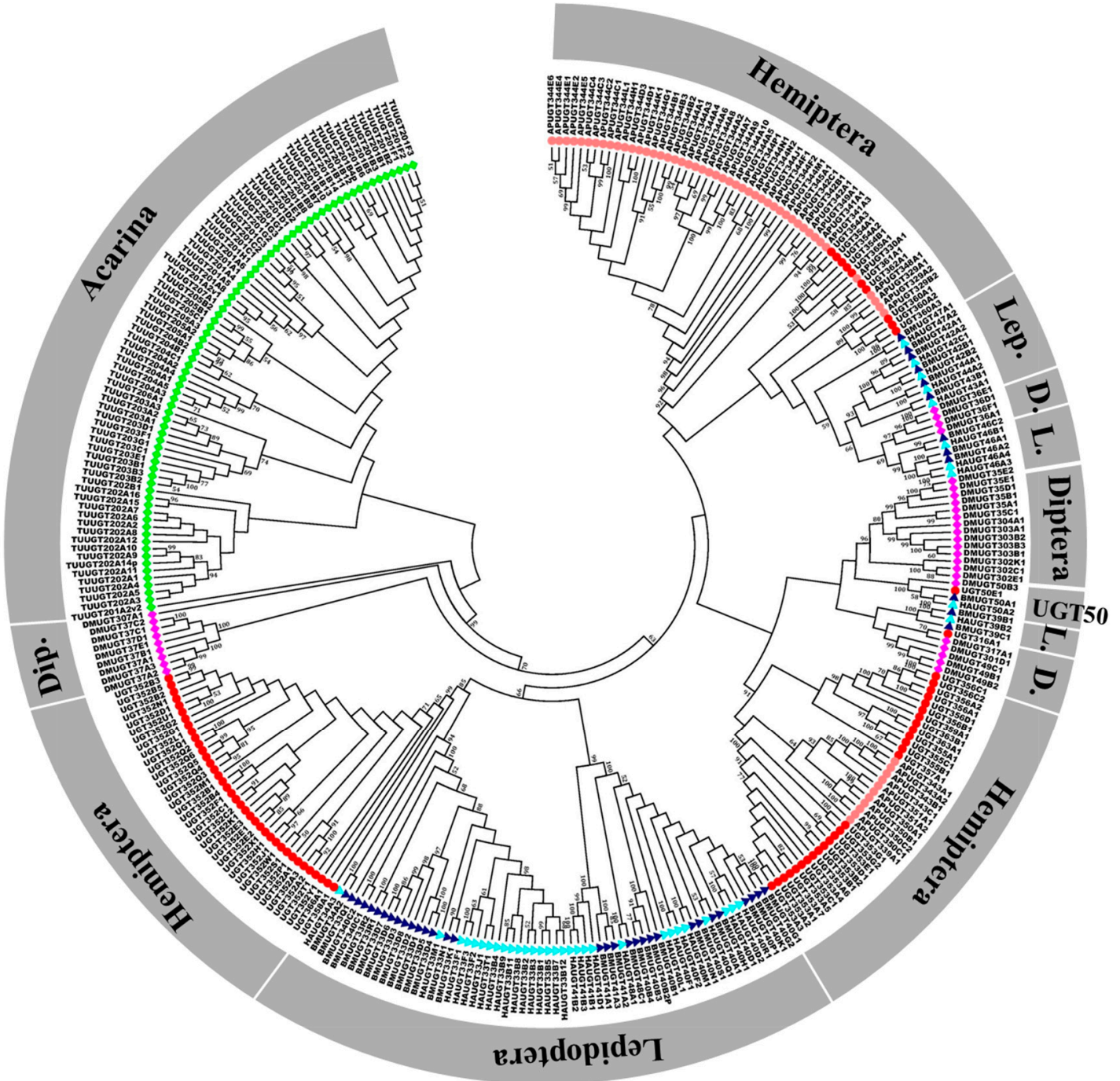

Figure 3. Phylogenetic relationships among UDP-glucuronosyltransferases (UGTs) in B. tabaci MEAM1 and other organisms. The amino acid sequences of full-length UGTs were aligned using ClustalW and subjected to a neighbor-joining (NJ) analysis by MEGA6 [42]. Numbers at the branch points of the nodes represent the values resulting from 1000 replications. Hemiptera: The dark red represents Bemisia tabaci, light red represents Acyrthosiphon pisum (Ap); Lepidoptera: the dark blue represents Bombyx mori $(\mathrm{Bm})$, light blue represents Helicoverpa armigera (Ha); Diptera: the pink represents Drosophila melanogaster (Dm); Arachnoidea: the green represents Tetranychus urticae (Tu).

RNA-seq data were also used to investigate how the expression profiles of UGTs were affected by different developmental stages of B. tabaci MEAM1 (Figure 5). The results revealed that UGT354A1 was the most highly expressed among the UGTs in the 1st-2nd instars (N1-2) and in the adults (F and M). In the 3rd instars (N3) and the 4th instars (N4), the expression of UGT362A1 was the highest. In the eggs (E), the expression of UGT352B1 was the highest. The expression levels of only 18 UGT genes (UGT352B1, UGT352E1, UGT353A6, UGT353A7, UGT353B2, UGT353C1, UGT353G2, UGT354A1, UGT354A2, UGT354A3, UGT355B1, UGT356A1, UGT356B1, UGT357A1, UGT359A1, UGT360A2, UGT362A1, UGT365A1) were more than two folds through all developmental stages (Table S3). Other notable features included: (i) UGT363A1 and UGT356D1 were not expressed in egg stage or the 1st2nd instars (N1-2); (ii) UGT356D1 had the lowest expression in the 3rd instars (N3); (iii) UGT353A2, UGT352J1 and UGT352M1 were not expressed in the 4th instars (N4); (iv) UGT352S1 and UGT352M1 were not expressed in the female (F); and (v) UGT352Q3, UGT360A1, UGT352W1 and UGT352M1 were not expressed in the male (M). Most of UGT genes were expressed at very low levels through 
their developmental stages. Together, these results suggest that most UGTs are likely subject to fine-scale regulations.
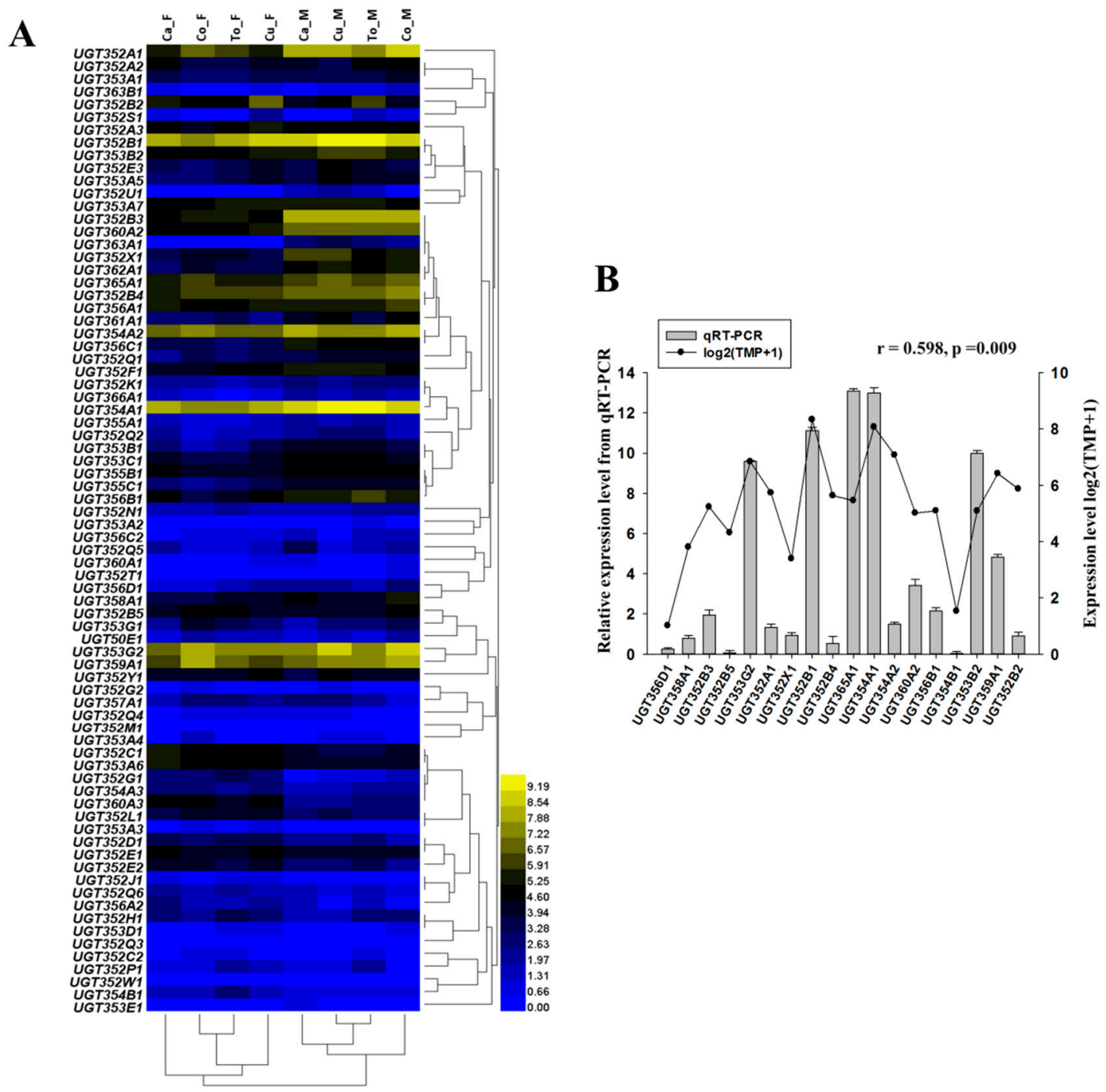

Figure 4. Expression profiling of UGT genes in MEAM1 was assessed using transcriptome data and RT-qPCR. (A) Expressions profiles of UGT genes in male and female adults that fed on four different host plants. The codes on the left are the gene ID numbers of the 76 UGTs in B. tabaci MEAM1. The mRNA levels, as represented by $\log 2(\mathrm{TPM}+1)$ values, are shown in the gradient heat map with colors ranging from blue (low expression) to yellow (high expression). Ca_F, females reared on cabbage; Ca_M, males reared on cabbage; $\mathrm{Cu} \_\mathrm{F}$, females reared on cucumber; $\mathrm{Cu} \mathrm{M}$, males reared on cucumber; Co_F, females reared on cotton; Co_M, males reared on cotton; To_F, females reared on tomato; To_M, males reared on tomato. (B) mRNA expressions of selected B. tabaci MEAM1 UGT genes by RT-qPCR. The bars represent expression level of $B$. tabaci MEAM1 UGT genes relative to the UGT352X. Data are presented as means \pm SE. Spots indicated $\log 2(\mathrm{TMP}+1)$ values of UGT genes in Ca_F. Correlation between RNA-seq and RT-qPCR were tested using SPSS with Pearson and two-tailed test, $r$, Pearson correlation; $p$, significant. 


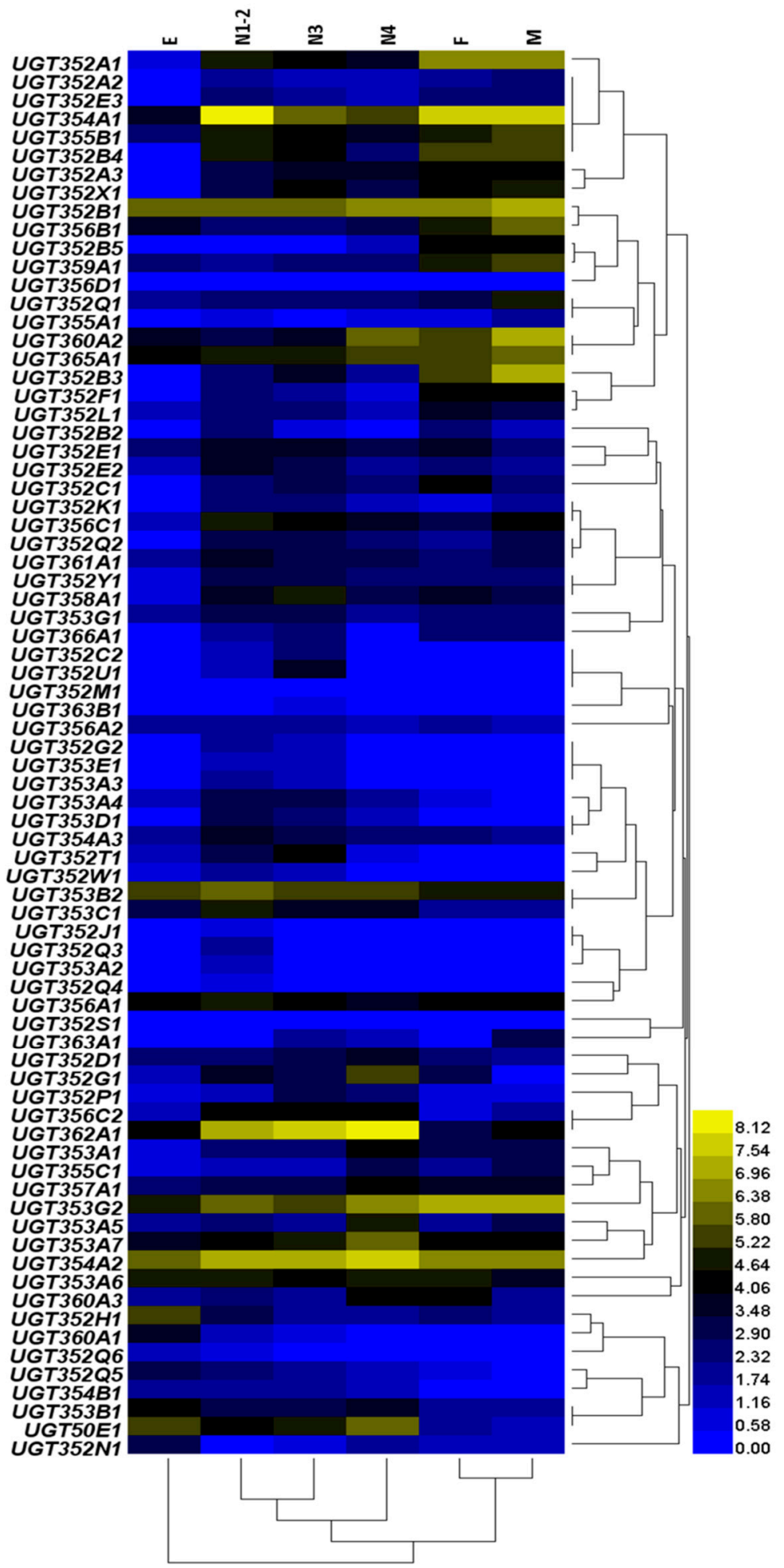

Figure 5. Gene expressions of UGTs across different developmental stages from MEAM1. The codes on the left are the gene ID numbers of the 76 UGTs in B. tabaci MEAM1. The mRNA levels, as represented by $\log 2(\mathrm{TPM}+1)$ values, are shown in the gradient heat map with colors ranging from blue (low expression) to yellow (high expression). E, egg; N1-2, 1st- and 2nd- instar nymphs; N3, 3rd- instar nymphs; N4, 4th- instar nymphs; F, adult female; $\mathrm{M}$, adult male. 


\section{3. mRNA Expressions of Selected UGT Genes by RT-qPCR}

For the UGT genes showing high expression levels in the RNA-seq data, their expression profiles were further confirmed by RT-qPCR (Figure 4). 14 UGT genes (UGT352A1, UGT352B1, UGT352B2, UGT352B3, UGT352B4, UGT352X1, UGT353B2, UGT353G2, UGT354A1, UGT354A2, UGT356B1, UGT359A1, UGT360A2, UGT365A1) had distinct high expression (yellow) in B. tabaci MEAM1 feeding on different host plants, and UGT352B5, UGT358A1, UGT356D1, UGT354B1 had low expression (black and blue). Therefore, we selected these 18 UGT genes to verify the expression by RT-PCR. Among the 18 genes analyzed, UGT354B1 had the highest expressional level, followed by UGT352B5, UGT352B4 which was slightly different from the RNA-seq data. However, statistical analysis by SPSS 17.0 showed an overall significant correlation between the RNA-seq data and RT-qPCR data $(\mathrm{r}=0.598, p=0.009)$.

\subsection{Effect of RNAi of UGTs on B. tabaci MEAM1 Adaptability}

To investigate the potential functions of UGTs in B. tabaci MEAM1, three UGTs were cloned and dsRNAs of the three UGTs were synthesized and separately fed to B. tabaci MEAM1 adults. The expression levels of UGT352A1, UGT352B1 and UGT354A1 were significantly suppressed after feeding with the dsRNAs (Figure 6). After feeding on the dsRNAs for $48 \mathrm{~h}$, the female adults were transferred to cabbage for $72 \mathrm{~h}$. At the phenotype level, while the survival of the female adults was not significantly different from the negative control, the number of eggs that an individual female laid was significantly reduced compared to those fed with dsEGFP (Figure 6).

A

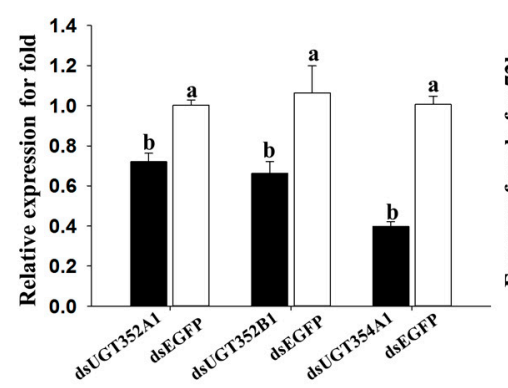

B

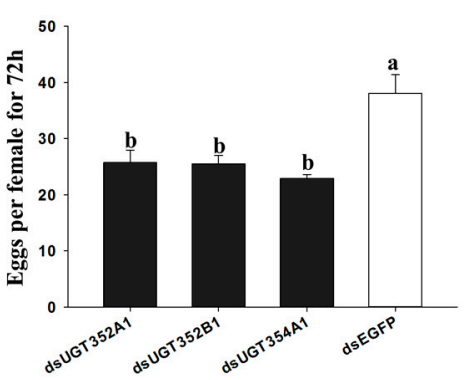

C

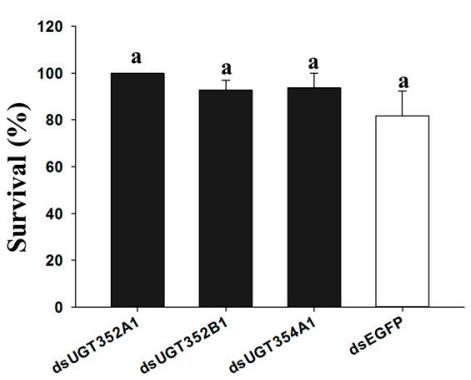

Figure 6. Silencing of UGT genes expression by oral feeding of dsRNA. (A) Suppression of UGT gene expression after B. tabaci MEAM1 adults were fed dsRNA for $48 \mathrm{~h}$, with adults fed dsEGFP as a control. The expression of UGT genes was detected by RT-qPCR with EF1- $\alpha$ as the internal reference gene. (B) Effect of silencing UGT genes on B. tabaci MEAM1 fecundity (fecundity at $72 \mathrm{~h}$ per female after feeding on cabbage). (C) Effect of silencing UGT genes on B. tabaci MEAM1 survival (survival at $48 \mathrm{~h}$ after feeding on dsRNA). Different letters above the bars indicate significant differences between treatments $(p<0.05$; Tukey's test; $n=4)$.

\section{Discussion}

In the present study, 76 UGT genes were identified in the $B$. tabaci MEAM1 genome (Table S1). This number of UGTs in B. tabaci MEAM1 is similar to number found in generalist insects (Acyrthosiphon pisum, 72 genes; Locusta migratoria, 68 genes) and mites (Tetranychus urticae, 81 genes) [41]. Consistent with previous results, the UGT genes in the polyphagous $B$. tabaci was more than those in the oligophagous insects feeding on plants, such as Rhodnius prolixus (16 genes) and Apis mellifera (11 genes) [38]. Table 1 summarized the number of UGT genes and feeding habits of 17 different insects (Table 1). We found that the number of UGT genes in non-phytophagous insects was generally low and in phytophagous insects, the number of UGT genes in polyphagous insects was higher than non-polyphagous insects (Table 1). These results are consistent with the hypothesis that the diversity of plant diet is a significant factor for UGT gene abundance in phytophagous insect genomes. 
Our phylogenetic analysis identified a remarkable expansion of the UGT352 and UGT353 families in the B. tabaci MEAM1 genome. Our result was similar to the observed high number of genes in UGT344 family in Acyrthosiphon pisum, UGT201 family in Tetranychus urticae, and UGT33 family in Helicoverpa armigera where each of them showed significant expansion in their respective genomes. Based on the cluster patterns in Figure 3, those clustered closely to each other likely have similar origins and functions. In the B. tabaci MEAM1 genome, the examples include UGT316A1 and DMUGT317A1 in one branch; UGT50E1, BMUGT50A1, HAUGT50A2 and DMUGT50B3 in one branch; UGT361A1, UGT362A1 and APUGT330A1 in one branch; and UGT360A1, UGT360A2, UGT360A3, APUGT329A1, APUGT329A2 and APUGT329B2 in one branch. Previous studies have shown that the generalist species A. pisum, T. urticae and H. armigera, are able to thrive on many hosts and that their UGTs showed differential expressions among the hosts. For example, UGT genes were suggested as playing important roles in the adaptation mechanism of T. urticae [22]. Similarly, the expansion of UGTs in Anoplophora glabripennis was thought to be related to its ability to feed on a broad range of host plants [23]. Therefore, we infer that the greatly expanded UGT genes in B. tabaci are at least partly related to its broad host range.

Insect UGT genes play diverse roles, including detoxification, digestion, olfaction and pigmentation and they are expressed in many different tissues [15,43]. The over-expressions of UGT genes in insecticide-resistant insects have been reported in Leptinotarsa decemlineata (Say), Plutella xylostella (L.), Diaphorina citri Kuwayama, Tetranychus cinnabarinus (Boisduval), Anopheles sinensis Wiedemann and Aphis gossypii Glover [43-48]. It has also been reported that UGTs were induced by insecticide exposures in Spodoptera exigua (Hübner) and Bemisia tabaci (Gennadius) $[49,50]$. However, detoxification by insect UGTs as a mechanism of adaptation to host plants has not been demonstrated. In our study, more UGT genes showed differential expression when fed with different host plants (37 UGT genes) than among different development stages with the same diet (18 UGT genes) (Table S3). Together, our results suggest that UGT gene expressions in $B$. tabaci are likely more related to host adaptation than to its development.

In general, insect adaptation to host plants is measured by comparing trait values (e.g., fecundity, survival, acceptance) [2]. To test whether the observed expression differences among UGTs were associated with adaptation to host plants, we selected three UGT genes (UGT352A1, UGT352B1 and UGT354A1) and tested their knockdown effects on adult females through RNAi, using cabbage as the diet. Our results showed the fecundity of female B. tabaci MEAM1 was reduced in all three RNAi treatments, supporting their potential role in host adaptation of $B$. tabaci to cabbage. Our results are also consistent with previous research results on the role of UGTs in host adaptation in other phytophagous insects [17-22]. For example, nine UGT genes in three insects (HAUGT41B3 and HAUGT40D1 in H. armigera [16]; TUUGT204B2, TUUGT202A2, and TUUGT202A15 in T. urticae [11]; and UGT330A3, UGT344D5, UGT348A3, and UGT349A3 in Myzus persicae) [51] were associated with the detoxification of plant secondary metabolites, specifically gossypol, flavonoid and nicotine by the three insect species. As shown in Figure 3, UGT354A1 was closely related to subfamilies of APUGT330A, APUGT344D, APUGT348A, and APUGT349A. The knockdown expressions of three UGT genes (UGT352A1, UGT352B1 and UGT354A1) by RNAi in B. tabaci MEAM1 reduced the its fecundity (Figure 6). The results suggest that UGT354A1 expression likely contributed to $B$. tabaci's tolerance and adaptation to secondary metabolites in cabbage. Interestingly, the T. urticae UGT genes showed a high degree of sequence similarity to those in bacteria [22]. Together with the lack of a signal peptide at the N-terminus and lack of the transmembrane domain at the C-terminus for the T. urticae UGT genes, the results suggested that the UGT genes in T. urticae were likely acquired from bacteria by horizontal gene transfer [22]. In our study, we found no robust evidence of horizontal gene transfer for any of the UGTs in the B. tabaci MEAMI genome. Specifically, none of the UGTs in the B. tabaci MEAMI genome was clustered with those in T. urticae nor with bacterial UGTs, consistent with those found by Chen et al. [41]. Indeed, 31 UGT genes, including UGT352B1, in B. tabaci MEAMI had no signal peptide in the N-terminus (Table S1), one of the criteria used for identifying eukaryotic genes of 
potential bacterial origin. Our results here provide foundations from which to further investigate the roles of specific UGTs in pest adaptation to additional host plants and potential mechanisms for their controls and managements.

\section{Materials and Methods}

\subsection{Insect Strain}

B. tabaci MEAM1 (Middle East- Asia Minor 1) were originally collected in 2004 from a field of cabbage, Brassica oleracea L. cv. Jingfeng 1, in Beijing, China [28]. The B. tabaci MEAM1 insects used in this study were reared on cabbage, in a glasshouse with natural light and controlled temperature $\left(26 \pm 2{ }^{\circ} \mathrm{C}\right)$. The method used for monitoring our experimental populations was the same as that described previously [52].

\subsection{Identification of UGTs in B. tabaci and Other Insects}

To identify the putative UGT genes in the B. tabaci MEAM1 genome, we searched the genome (http://www.whiteflygenomics.org) [41] and transcriptome [53] (SRP064690) databases of B. tabaci MEAM1. Specifically, first, we used the annotated UGT genes from Drosophila melanogaster and Acyrthosiphon pisum as queries for homolog searches in the B. tabaci MEAM1 genome. Second, the identified putative homologs were annotated by blasting against the non-redundant (NR) protein sequence database of GenBank (http:www.ncbi.nlm.nih.gov/) with the blastp program [54]. Finally, the identified UGTs were searched against B. tabaci transcriptome database [42] (SRP064690) using the tblastn program [54], with manual checking and confirmation for each gene. According to the current nomenclature guidelines of the UGT Nomenclature Committee, preliminary grouping was done using the program H-CD-HIT [55] at $60 \%$ and $40 \%$ sequence identity as cut off values, and preliminary family and subfamily names were assigned on this basis.

\subsection{Phylogenetic Analysis of B. tabaci MEAM1 UGT Genes}

To understand the evolutionary relationship among the UGT genes within B. tabaci MEAM1 and between these UGT genes and those in several other insects, we retrieved the UGT sequences of Acyrthosiphon pisum (Ap), Bombyx mori (Bm), Helicoverpa armigera (Ha), Drosophila melanogaster (Dm), Tetranychus urticae (Tu) using the annotations in previous reports $[15,22,56]$. All the selected UGT amino acid sequences were aligned using ClustalW, a module of MEGA 6 [42]. A phylogenetic tree was constructed based on the aligned UGT protein sequences using the neighbor-joining (NJ) method based on the Jones-Taylor-Thornton (JTT) model with a uniform substitution rate combined with pairwise deletion and 1000 bootstrap replicates.

\subsection{Expression profiling of UGT Genes}

Expression profiling of UGT genes in B. tabaci MEAM1 was assessed using transcriptome data of different developmental stages and four different host plants (cabbage, cucumber, cotton, and tomato) as described earlier [57]. The RNA-seq data and processing method were the same as our previous report [57]. The relative expression levels of UGT genes were also verified through RT-qPCR (ABI 7500 Real-Time PCR system (Applied Biosystems, Forster city CA, USA)). Total RNA was extracted using Trizol reagent according to the manufacturer's instructions (Invitrogen, Carlsbad, CA, USA). RNA was quantified using a Nanodrop 2000 (Thermo Scientific, Wilmington, DE, USA) and its purity was checked on 1\% agarose gel. Gene-specific primers for 18 UGT genes were designed and used in PCR reactions. Each RT-qPCR reaction $(20 \mu \mathrm{L})$ contained $7 \mu \mathrm{L}$ ddH2O, $10 \mu \mathrm{L}$ of $2 \times$ SuperReal PreMix Plus (TIANGEN, Beijing, China), $0.8 \mu \mathrm{L} 10 \mu \mathrm{M}$ of each specific primer, $1 \mu \mathrm{L}$ first-strand cDNA template and $0.4 \mu \mathrm{L}$ of $50 \times$ ROX Reference Dye (TIANGEN). The RT-qPCR program consisted of an initial denaturation at $95^{\circ} \mathrm{C}$ for $15 \mathrm{~min}$ followed by 40 cycles of denaturation at $95^{\circ} \mathrm{C}$ for $15 \mathrm{~s}$, annealing at $60{ }^{\circ} \mathrm{C}$ for $30 \mathrm{~s}$ and extension at $72{ }^{\circ} \mathrm{C}$ for $32 \mathrm{~s}$. The translation elongation factor 1 alpha gene $(\mathrm{EF}-1 \alpha)$ 
(GenBank accession NO. EE600682) [58] was used as reference gene and relative gene expression was calculated using the $2^{\Delta \Delta C T}$ method [59]. Four technical replicates and three biological replicates were used for each treatment. Sequences of all primers used in this study are listed in Supporting Information Table S2. All gene primer amplification efficiencies were between 95-105\%.

\subsection{RNA Interference}

The expression of UGT352B1 and UGT354A1 was the highest in transcriptome data of different host plants and RT-PCR data, and these three genes expressions differed significantly among the host plants (See Results below). Therefore, three UGT genes, UGT352A1, UGT352B1 and UGT354A1, were selected for RNAi. In our RNAi experiment, the dsRNA for enhanced green fluorescent protein (EGFP) was used as the negative control. The dsRNA primers of UGT352A1, UGT352B1, UGT354A1 and EGFP (GenBank: KC896843) are listed in Table S2. The dsRNAs were prepared according to the T7 RiboMAX Express RNAi system protocols (Promega, Madison, USA). The RNAi bioassay was performed by directly feeding dsRNA to $B$. tabaci adults in a feeding chamber for $48 \mathrm{~h}$. A 0.20-mL drop of diet solution that contained $5 \%$ yeast extract and $30 \%$ sucrose (wt/vol) with $100 \mathrm{ng}$ of dsRNA was placed in the chamber. The details of feeding were performed as described in a previous study [60]. Approximately 60 adults (mixed sexes) were used for RNAi treatment of each UGT gene, and each treatment repeated four times. The experiment was conducted in an environmental chamber at $26{ }^{\circ} \mathrm{C}$, a photoperiod of L14: D10, and 80\% RH. After $48 \mathrm{~h}$, five females were randomly selected and transferred to cabbage to lay eggs for $72 \mathrm{~h}$. The remaining whitefly adults were collected for analysis of the expression levels of targeted UGT genes. The survival rate of the female and the number of eggs that they laid were recorded.

\subsection{Statistical Analysis}

One-way ANOVA was used to compare the gene expression levels and survival rates among different treatments. Means were compared with Tukey's tests at $p<0.05$. SPSS version 17.0 (SPSS Inc., Chicago, IL, USA) was used for statistical analyses.

Supplementary Materials: Supplementary materials can be found at http://www.mdpi.com/1422-0067/21/22/ 8492/s1.

Author Contributions: L.G., J.X. and Y.Z. conceived and designed the experiments; L.G. and W.X. performed the experiments and wrote the main manuscript text; W.X. and Z.Y. helped interpret the data; All authors have read and agreed to the published version of the manuscript.

Funding: This research was supported by National Natural Science Foundation of China (31701818), Natural Science Foundation of Hunan (2018JJ3582), the Science and Technology Innovation Program of the Chinese Academy of Agricultural Sciences (CAAS-ASTIP-IVF and CAAS-ASTIP-IBFC) and the Beijing Key Laboratory for Pest Control and Sustainable Cultivation of Vegetables. The funding agencies had no role in study design, data collection and analysis, decision to publish, or preparation of the manuscript.

Conflicts of Interest: The authors declare no conflict of interest.

\section{Abbreviations}

$\begin{array}{ll}\text { UDP } & \text { Uridine diphosphate } \\ \text { UGTs } & \text { Uridine diphosphate glucuronosyltransferases } \\ \text { EF-1 } \alpha & \text { The translation elongation factor } 1 \text { alpha gene } \\ \text { MEAM1 } & \text { Middle East-Asia Minor } 1 \\ \text { TPM } & \text { Transcripts Per Million }\end{array}$

\section{References}

1. Liu, P.; Ma, H.; Zhu, Q.S.; Chen, B.C.; Gao, J.; Lin, X.Q. Research progress of insect adaptability to their host plants. Biol. Disaster Sci. 2016, 39, 250-254. 
2. Sousa, V.C.; Zélé, F.; Rodrigues, L.R.; Godinho, D.P.; de la Masselière, M.C.; Magalhães, S. Rapid host-plant adaptation in the herbivorous spider mite Tetranychus urticae occurs at low cost. Curr. Opin. Insect Sci. 2019, 36, 82-89. [CrossRef] [PubMed]

3. Grbic, M.; Van Leeuwen, T.; Clark, R.M.; Rombauts, S.; Rouze, P.; Grbic, V.; Osborne, E.J.; Dermauw, W.; Ngoc, P.C.T.; Ortego, F.; et al. The genome of Tetranychus urticae reveals herbivorous pest adaptations. Nature 2011, 479, 487-492. [CrossRef] [PubMed]

4. Santamaría, M.E.; Hernández-Crespo, P.; Ortego, F.; Grbic, V.; Grbic, M.; Diaz, I.; Martinez, M. Cysteine peptidases and their inhibitors in Tetranychus urticae: A comparative genomic approach. BMC Genom. 2012, 13, 307. [CrossRef]

5. Dermauw, W.; Osborne, E.J.; Clark, R.M.; Grbic, M.; Tirry, L.; Van Leeuwen, T. A burst of ABC genes in the genome of the polyphagous spider mite Tetranychus urticae. BMC Genom. 2013, 14, 317. [CrossRef]

6. Dermauw, W.; Wybouw, N.; Rombauts, S.; Menten, B.; Vontas, J.; Grbic, M.; Clark, R.M.; Feyereisen, R.; Van Leeuwen, T. A link between host plant adaptation and pesticide resistance in the polyphagous spider mite Tetranychus urticae. Proc. Natl. Acad. Sci. USA 2013, 110, E113-E122. [CrossRef]

7. Wybouw, N.; Balabanidou, V.; Ballhorn, D.J.; Dermauw, W.; Grbić, M.; Vontas, J.; Van Leeuwen, T. A horizontally transferred cyanase gene in the spider mite Tetranychus urticae is involved in cyanate metabolism and is differentially expressed upon host plant change. Insect Biochem. Mol. Biol. 2012, 42, 881-889. [CrossRef]

8. Wybouw, N.; Dermauw, W.; Tirry, L.; Stevens, C.; Grbic, M.; Feyereisen, R.; Van Leeuwen, T. A gene horizontally transferred from bacteria protects arthropods from host plant cyanide poisoning. eLife 2014, 3, e02365. [CrossRef]

9. Wybouw, N.; Van Leeuwen, T.; Dermauw, W. A massive incorporation of microbial genes into the genome of Tetranychus urticae, a polyphagous arthropod herbivore. Insect Mol. Biol. 2018, 27, 333-351. [CrossRef]

10. Schlachter, C.R.; Daneshian, L.; Amaya, J.; Klapper, V.; Wybouw, N.; Borowski, T.; Van Leeuwen, T.; Grbic, V.; Grbic, M.; Makris, T.M.; et al. Structural and functional characterization of an intradiol ring-cleavage dioxygenase from the polyphagous spider mite herbivore Tetranychus urticae Koch. Insect Biochem. Mol. Biol. 2019, 107, 19-30. [CrossRef]

11. Snoeck, S.; Pavlidi, N.; Dermauw, W.; Van Leeuwen, T. Substrate specificity and promiscuity of UDP-glycosyltransferases in the polyphagous arthropod Tetranychus urticae. Insect Biochem. Mol. Biol. 2019, 109, 116-127. [CrossRef] [PubMed]

12. Wybouw, N.; Zhurov, V.; Martel, C.; Bruinsma, K.A.; Hendrickx, F.; Grbić, V.; Van Leeuwen, T. Adaptation of a polyphagous herbivore to a novel host plant extensively shapes the transcriptome of herbivore and host. Mol. Ecol. 2015, 24, 4647-4663. [CrossRef] [PubMed]

13. Zhurov, V.; Navarro, M.; Bruinsma, K.A.; Arbona, V.; Estrella Santamaria, M.; Cazaux, M.; Wybouw, N.; Osborne, E.J.; Ens, C.; Rioja, C.; et al. Reciprocal responses in the interaction between Arabidopsis and the cell-content-feeding chelicerate herbivore spider mite. Plant. Physiol. 2014, 164, 384-399. [CrossRef] [PubMed]

14. Snoeck, S.; Wybouw, N.; Van Leeuwen, T.; Dermauw, W. Transcriptomic plasticity in the arthropod generalist Tetranychus urticae upon long-term acclimation to different host plants. G3 Genes Genomes Genet. 2018, 8, 3865-3879. [CrossRef]

15. Ahn, S.J.; Vogel, H.; Heckel, D.G. Comparative analysis of the UDP-glycosyltransferase multigene family in insects. Insect Biochem. Mol. Biol. 2012, 42, 133-147. [CrossRef]

16. Krempl, C.; Sporer, T.; Reichelt, M.; Ahn, S.J.; Heidel-Fischer, H.; Vogel, H.; Heckel, D.G.; Jouben, N. Potential detoxification of gossypol by UDP-glycosyltransferases in the two Heliothine moth species Helicoverpa armigera and Heliothis virescens. Insect Biochem. Mol. Biol. 2016, 71, 49-57. [CrossRef]

17. Govind, G.; Mittapalli, O.; Griebel, T.; Allmann, S.; Böcker, S.; Baldwin, I.T. Unbiased transcriptional comparisons of generalist and specialist herbivores feeding on progressively defenseless Nicotiana attenuata plants. PLoS ONE 2010, 5, e8735. [CrossRef]

18. Celorio-Mancera, M.P.; Heckel, D.G.; Vogel, H. Transcriptional analysis of physiological pathways in a generalist herbivore: Responses to different host plants and plant structures by the cotton bollworm, Helicoverpa armigera. Entomol. Exp. Appl. 2012, 144, 123-133. [CrossRef]

19. De la Paz, C.-M.M.; Wheat, C.W.; Vogel, H.; Söderlind, L.; Janz, N.; Nylin, S. Mechanisms of macroevolution: Polyphagous plasticity in butterfly larvae revealed by RNA-Seq. Mol. Ecol. 2013, 22, 4884-4895. [CrossRef] 
20. Ragland, G.J.; Almskaar, K.; Vertacnik, K.L.; Gough, H.M.; Feder, J.L.; Hahn, D.A.; Schwarz, D. Differences in performance and transcriptome-wide gene expression associated with Rhagoletis (Diptera: Tephritidae) larvae feeding in alternate host fruit environments. Mol. Ecol. 2015, 24, 2759-2776. [CrossRef]

21. Xu, H.X.; Hong, Y.; Zhang, M.Z.; Wang, Y.L.; Liu, S.S.; Wang, X.W. Transcriptional responses of invasive and indigenous whiteflies to different host plants reveal their disparate capacity of adaptation. Sci. Rep. 2015, 5, 10774. [CrossRef] [PubMed]

22. Ahn, S.J.; Dermauw, W.; Wybouw, N.; Heckel, D.G.; Leeuwen, T.V. Bacterial origin of a diverse family of UDP-glycosyltransferase genes in the Tetranychus urticae genome. Insect Biochem. Mol. Biol. 2014, 50, 43-57. [CrossRef] [PubMed]

23. McKenna, D.D.; Scully, E.D.; Pauchet, Y.; Hoover, K.; Kirsch, R.; Geib, S.M.; Mitchell, R.F.; Waterhouse, R.M.; Ahn, S.J.; Arsala, D.; et al. Genome of the Asian longhorned beetle (Anoplophora glabripennis), a globally significant invasive species, reveals key functional and evolutionary innovations at the beetle-plant interface. Genome Biol. 2016, 17, 227. [CrossRef]

24. Brown, J.K.; Frohlich, D.R.; Rosell, R.C. The sweetpotato or silverleaf whiteflies: Biotypes of Bemisia tabaci or a species complex? Ann. Rev. Entomol. 1995, 40, 511-534. [CrossRef]

25. De Barro, P.J.; Liu, S.S.; Boykin, L.M.; Dinsdale, A. Bemisia tabaci: A statement of species status. Ann. Rev. Entomol. 2011, 56, 1-19. [CrossRef]

26. Delatte, H.; Duyck, P.; Triboire, A.; David, P.; Becker, N.; Bonato, O.; Rrynaud, B. Differential invasion success among biotypes: Case of Bemisia tabaci. Biol. Invasion 2009, 11, 1059-1070. [CrossRef]

27. Dinsdale, A.; Cook, L.; Riginos, C.; Buckley, Y.M.; De Barro, P. Refined global analysis of Bemisia tabaci (Hemiptera: Sternorrhyncha: Aleyrodoidea: Aleyrodidae) mitochondrial cytochrome oxidase 1 to identify species level genetic boundaries. Ann. Entomol Soc. Am. 2010, 103, 196-208. [CrossRef]

28. Pan, H.; Chu, D.; Yan, W.Q.; Su, Q.; Liu, B.M.; Wang, S.L.; Wu, Q.J.; Xie, W.; Jiao, X.G.; Li, R.M.; et al. Rapid spread of Tomato yellow leaf curl virus in China is aided differentially by two invasive whiteflies. PLoS ONE 2012, 7, e34817. [CrossRef]

29. Gilbertson, R.L.; Batuman, O.; Webster, C.G.; Adkins, S. Role of the insect supervectors Bemisia tabaci and Frankliniella occidentalis in the emergence and global spread of plant viruses. Ann. Rev. Virol. 2015, 2, 67-93. [CrossRef]

30. Zang, L.S.; Chen, W.Q.; Liu, S.S. Comparison of performance on different host plants between the B biotype and a non-B biotype of Bemisia tabaci from Zhejiang, China. Entomol. Exp. Appl. 2006, 121, 221-227. [CrossRef]

31. Jiao, X.G.; Xie, W.; Guo, L.T.; Liu, B.M.; Wang, S.L.; Wu, Q.J.; Zhang, Y.J. Differing effects of cabbage and pepper on B and Q putative species of Bemisia tabaci. J. Pest. Sci. 2014, 87, 629-637. [CrossRef]

32. Jiao, X.G.; Xie, W.; Zeng, Y.; Wan, C.; Liu, B.M.; Wang, S.L.; Wu, Q.J.; Zhang, Y.J. Lack of correlation between host choice and feeding efficiency for the B and Q putative species of Bemisia tabaci on four pepper genotypes. J. Pest. Sci. 2018, 91, 133-143. [CrossRef]

33. Douglas, A.E. Phloem-sap feeding by animals: Problems and solutions. J. Exp. Bot. 2006, 57, 747-754. [CrossRef] [PubMed]

34. Cui, H.Y.; Guo, L.T.; Wang, S.L.; Xie, W.; Jiao, X.G.; Wu, Q.J.; Zhang, Y.J. The ability to manipulate plant glucosinolates and nutrients explains the better performance of Bemisia tabaci Middle East-Asia Minor 1 than Mediterranean on cabbage plants. Ecol. Evol. 2017, 7, 6141-6150. [CrossRef] [PubMed]

35. Guo, L.T.; Su, Q.; Yang, Z.Z.; Xie, W.; Wang, S.L.; Wu, Q.J.; Cui, H.Y.; Zhang, Y.J. Amino Acid Utilization May Explain Why Bemisia tabaci Q and B Differ in Their Performance on Plants Infected by the Tomato yellow leaf curl virus. Front. Physiol. 2019, 10, 489. [CrossRef]

36. Elbaz, M.; Halon, E.; Malka, O.; Malitsky, S.; Blum, E.; Aharoni, A.; Morin, S. Asymmetric adaptation to indolic and aliphatic glucosinolates in the B and Q sibling species of Bemisia tabaci (Hemiptera: Aleyrodidae). Mol. Ecol. 2012, 21, 4533-4546. [CrossRef] [PubMed]

37. Markovich, O.; Kafle, D.; Elbaz, M.; Malitsky, S.; Aharoni, A.; Schwarzkopf, A.; Gershenzon, J.; Morin, S. Arabidopsis thaliana plants with different levels of aliphatic- and indolyl-glucosinolates affect host selection and performance of Bemisia tabaci. J. Chem. Ecol. 2013, 39, 1361-1372. [CrossRef]

38. Zhang, X.; Sun, X.; Zhao, H.P.; Xue, M.; Wang, D. Phenolic compounds induced by Bemisia tabaci and Trialeurodes vaporariorum in Nicotiana tabacum L. and their relationship with the salicylic acid signaling pathway. Arthropod Plant. Interact. 2017, 11, 659-667. [CrossRef] 
39. Yang, J.; Xie, W.; Liu, B.; Wang, S.; Wu, Q.; He, Y.; Zhang, Y.; Jiao, X. Phenolics, rather than glucosinolates, mediate host choice of Bemisia tabaci MEAM1 and MED on five cabbage genotypes. J. Appl. Entomol. 2020, 144, 287-296. [CrossRef]

40. Mackenzie, P.I.; Owens, I.S.; Burchell, B.; Bock, K.W.; Bairoch, A.; Belanger, A.; FournelGigleux, S.; Green, M.; Hum, D.W.; Iyanagi, T.; et al. The UDP glycosyltransferase gene superfamily: Recommended nomenclature update based on evolutionary divergence. Pharmacogenetics 1997, 7, 255-269. [CrossRef]

41. Chen, W.B.; Hasegawa, D.K.; Kaur, N.; Kliot, A.; Pinheiro, P.V.; Luan, J.B.; Stensmyr, M.C.; Zheng, Y.; Liu, W.L.; Sun, H.H.; et al. The draft genome of whitefly Bemisia tabaci MEAM1, a global crop pest, provides novel insights into virus transmission, host adaptation, and insecticide resistance. BMC Biol. 2016, 14, 110. [CrossRef] [PubMed]

42. Tamura, K.; Stecher, G.; Peterson, D.; Filipski, A.; Kumar, S. MEGA6: Molecular Evolutionary Genetics Analysis version 6.0. Mol. Biol. Evol. 2013, 30, 2725-2729. [CrossRef] [PubMed]

43. Chen, X.W.; Tang, C.Y.; Ma, K.S.; Xia, J.; Song, D.L.; Gao, X.W. Overexpression of UDP-glycosyltransferase potentially involved in insecticide resistance in Aphis gossypii Glover collected from Bt cotton fields in China. Pest. Manag. Sci. 2019. [CrossRef] [PubMed]

44. Kaplanoglu, E.; Chapman, P.; Scott, I.M.; Donly, C. Overexpression of a cytochrome P450 and a UDP-glycosyltransferase is associated with imidacloprid resistance in the Colorado potato beetle, Leptinotarsa decemlineata. Sci. Rep. 2017, 7, 1762. [CrossRef]

45. Li, X.X.; Zhu, B.; Gao, X.W.; Liang, P. Over-expression of UDP-glycosyltransferase gene UGT2B17 is involved in chlorantraniliprole resistance in Plutella xylostella (L.). Pest. Manag. Sci. 2017, 73, 1402-1409. [CrossRef]

46. Wang, M.Y.; Liu, X.Y.; Shi, L.; Liu, J.L.; Shen, G.M.; Zhang, P.; Lu, W.C.; He, L. Functional analysis of UGT201D3 associated with abamectin resistance in Tetranychus cinnabarinus (Boisduval). Insect Sci. 2018, 27, 276-291. [CrossRef]

47. Tian, F.J.; Wang, Z.B.; Li, C.F.; Liu, J.L.; Zeng, X.N. UDP-Glycosyltransferases are involved in imidacloprid resistance in the Asian citrus psyllid, Diaphorina citri (Hemiptera: Lividae). Pestic. Biochem. Physiol. 2019, 154, 23-31. [CrossRef]

48. Zhou, Y.; Fu, W.B.; Si, F.L.; Yan, Z.T.; Zhang, Y.J.; He, Q.Y.; Chen, B. UDP-glycosyltransferase genes and their association and mutations associated with pyrethroid resistance in Anopheles sinensis (Diptera: Culicidae). Malar. J. 2019, 18, 62. [CrossRef]

49. Su, Q.; Li, S.X.; Shi, C.H.; Zhang, J.M.; Zhang, G.H.; Jin, Z.Y.; Li, C.R.; Wang, W.K.; Zhang, Y.J. Implication of heat-shock protein 70 and UDP-glucuronosyltransferase in thiamethoxam-induced whitefly Bemisia tabaci thermotolerance. J. Pest. Sci. 2018, 91, 469-478. [CrossRef]

50. Hu, B.; Zhang, S.H.; Ren, M.M.; Tian, X.R.; Wei, Q.; Mburu, D.K.; Su, J.Y. The expression of Spodoptera exigua P450 and UGT genes: Tissue specificity and response to insecticides. Insect Sci. 2019, 26, 199-216. [CrossRef]

51. Pan, Y.; Xu, P.; Zeng, X.; Liu, X.; Shang, Q. Characterization of UDP-Glucuronosyltransferases and the Potential Contribution to Nicotine Tolerance in Myzus Persicae. Int. J. Mol. Sci. 2019, 20, 3637. [CrossRef] [PubMed]

52. Chu, D.; Wan, F.H.; Zhang, Y.J.; Brown, J.K. Change in the biotype composition of Bemisia tabaci in Shandong Province of China from 2005 to 2008. Environ. Entomol. 2010, 39, 1028-1036. [CrossRef] [PubMed]

53. Xie, W.; Wu, Q.; Wang, S.; Jiao, X.; Guo, L.; Zhou, X.; Zhang, Y. Transcriptome analysis of host-associated differentiation in Bemisia tabaci (Hemiptera: Aleyrodidae). Front. Physiol. 2014, 5, 487. [CrossRef] [PubMed]

54. Altschul, S.F.; Madden, T.L.; Schaffer, A.A.; Zhang, J.; Zhang, Z.; Miller, W.; Lipman, D.J. Gapped BLAST and PSI-BLAST: A new generation of protein database search programs. Nucleic Acids Res. 1997, 25, 3389-3402. [CrossRef]

55. Li, W.; Godzik, A. CD-HIT: A fast program for clustering and comparing large sets of protein or nucleotide sequences. Bioinformatics 2006, 22, 1658-1659. [CrossRef]

56. Luque, T.; Okano, K.; O'Reilly, D.R. Characterization of a novel silkworm (Bombyx mori) phenol UDP-glucosyltransferase. Eur J. Biochem. 2002, 269, 819-825. [CrossRef]

57. Yang, Z.Z.; Xia, J.X.; Pan, H.P.; Cheng, G.; Xie, W.; Guo, Z.J.; Zheng, H.X.; Yang, X.; Yang, F.S.; Wu, Q.J.; et al. Genome-wide characterization and expression profiling of sugar transporter family in the whitefly, Bemisia tabaci (Gennadius) (Hemiptera: Aleyrodidae). Front. Physiol. 2017, 8, 322. [CrossRef] 
58. Li, R.; Xie, W.; Wang, S.; Wu, Q.; Yang, N.; Yang, X.; Pan, H.; Zhou, X.; Bai, L.; Xu, B.; et al. Reference gene selection for qRT-PCR analysis in the sweetpotato whitefly, Bemisia tabaci (Hemiptera: Aleyrodidae). PLoS ONE 2013, 8, e53006. [CrossRef]

59. Livak, K.J.; Schmittgen, T.D. Analysis of relative gene expression data using real-time quantitative PCR and the $2^{-\Delta \Delta C T}$ method. Methods 2001, 25, 402-408. [CrossRef]

60. Yang, X.; He, C.; Xie, W.; Liu, Y.; Xia, J.; Yang, Z.; Guo, L.; Wen, Y.; Wang, S.; Wu, Q.; et al. Glutathione S-transferases are involved in thiamethoxam resistance in the field whitefly Bemisia tabaci Q (Hemiptera: Aleyrodidae). Pestic. Biochem. Physiol. 2016, 134, 73-78. [CrossRef]

Publisher's Note: MDPI stays neutral with regard to jurisdictional claims in published maps and institutional affiliations.

(C) 2020 by the authors. Licensee MDPI, Basel, Switzerland. This article is an open access article distributed under the terms and conditions of the Creative Commons Attribution (CC BY) license (http://creativecommons.org/licenses/by/4.0/). 